\title{
Does repeated gold-nanoparticles administration affect pars distalis hormonal and folliculo-stellate cells in adult male albino rats?
}

\author{
Abeer Ibraheem Omar' ${ }^{1}$, Samaa Samir Kamar $^{1,2}{ }^{(\mathbb{D}}$ \\ ${ }^{1}$ Department of Histology and Cell Biology, Faculty of Medicine, Cairo University, Cairo, Egypt \\ ${ }^{2}$ Department of Histology, Armed Forces College of Medicine, Cairo, Egypt
}

\begin{abstract}
Introduction. Worldwide, nanoparticles especially gold-nanoparticles (Au-NPs) are widely used in medicine, cancer treatment and cosmetic industry. They are easily conjugated with different biomedical and biological agents and effortlessly absorbed with few side effects. The pars distalis of the pituitary gland is considered as the maestro of the endocrine peripheral glands since it secrets trophic hormones that controls their functions. 5-10\% of the non-granular pars distalis cells are folliculo-stellate cells (FSCs) that support the granular cells' functions. The aim of the study was to explore the histological and the biochemical effects of repeated exposure to Au-NPs on the pars distalis in adult male albino rats with highlighting the impact on FSCs.

Material and methods. Thirty-six adult male albino rats were divided equally into control group and Au-NPs group (received $40 \mu \mathrm{g} / \mathrm{kg} /$ day of $11 \pm 2 \mathrm{~nm}$ spherical Au-NPs orally for 2 weeks). Then, rats were euthanized and deposition of Au-NPs in pars distalis was investigated. Biochemical investigations and histological studies including hematoxylin and eosin staining, periodic acid Schiff's reaction, immunohistochemistry (IHC) for S-100, connexin $43(\mathrm{Cx} 43)$ and Cytochrome-C (Cyt-C) as well as electron-microscopic and morphometric studies were carried out.

Results. The Au-NPs group demonstrated structural disorganization in the pars distalis, inflammation, congestion and increased extracellular PAS-positive colloid deposition due to the accumulation of Au-NPs. A significant increase in the immunoreactivity of S-100, Cx43 and Cyt-c, along with a significant increase in TNF- $\alpha$, MDA, and bFGF content in the pituitary homogenates, was noted as compared to the control group. Ultrastructurally, degenerative changes were observed in the secretory cells. FSCs showed proliferation and increased phagocytic activity.

Conclusions. Repetitive exposure of adult male albino rats to Au-NPs prompted the accumulation of these nanoparticles in the pars distalis that was accompanied by cellular degeneration and dysfunction of the secretory cell and proliferation of FSCs. Thus, monitoring of the pars distalis hormonal levels might be useful for early detection of some hazardous effects possibly associated with the use of gold-nanoparticles. (Folia Histochemica et Cytobiologica 2021, Vol. 59, No. 2, 95-107)
\end{abstract}

Key words: gold-nanoparticles; rat; pars distalis; folliculo-stellate cells; connexin 43; cytochrome-c; IHC; electron microscopy

Correspondence address: Samaa Samir Kamar

Department of Histology and Cell Biology,

Faculty of Medicine, Cairo University, El Manial,

11559, Cairo, Egypt

phone: +0201008909069

e-mail: Dr_samaakamar@yahoo.com

\section{Introduction}

Nanoparticles are materials that are naturally present or can be engineered from carbon or other elements like silver and gold. They have characteristic tiny sizes (less than 100 nanometers) with high surface

This article is available in open access under Creative Common Attribution-Non-Commercial-No Derivatives 4.0 International (CC BY-NC-ND 4.0) license, allowing to download articles and share them with others as long as they credit the authors and the publisher, but without permission to change them in any way or use them commercially. 
area to volume ratio. Such unique minute size gives them physical, electrical and optical properties. So, they are widely used in different industries like cosmetics, beverages and food packaging [1]. Moreover, their ability to enter the mammalian body through inhalation, ingestion or cutaneous absorption was proved [2]. As well, they are capable of modifying the drugs' pharmacokinetics and pharmacodynamics affecting the distribution of the drugs in different tissues [3].

Among the nanoparticles, gold nanoparticles (Au-NPs) are widely used for labelling, imaging (pacemakers and stents), implants and delivery in medicine, pharmacy and cosmetic industry $[4,5]$. In addition, Au-NPs are promisingly used as a vehicle for the chemotherapeutic agents in the treatment of cancers for better targeting of the cancer cells and use of smaller chemotherapies' doses with fewer side effects [6]. Moreover, Au-NPs are used in photothermolysis of cancer cells [7]. Furthermore, they can be utilized to spot and limit growth of certain microorganisms [8] and to be formulated in vaccines for certain diseases depending on their adjuvant characteristics and induction of a humoral immune response [9]. The wide use of Au-NPs depends on their unique ability to be conjugated with various types of biological, biophysical and biomedical agents such as drugs, vaccines, proteins, DNA, RNA and others [2]. Additionally, they can be absorbed easily with fewer hazardous effects than other nanoparticles [10] and can control the drug release inside the target cells [11].

It was previously documented that single and repeated systemic administration of the nanoparticles is followed by their presence in large amounts in liver and spleen and in small quantities in other organs such as brain, heart, lungs, and kidneys [12,13]. As well, repeated oral intake and intraperitoneal injections of Au-NPs was recorded to be followed by its appearance in numerous mice tissues [12]. Of note, the matter of safety of these nanoparticles becomes an important health issue that can should be first resolved based on in vivo experiments.

The pituitary gland, the master endocrine gland, is considered as an intermediate body between hypothalamus and peripheral endocrine organs [14]. It is divided into two parts, the adenohypophysis that comprises the pars distalis, pars intermedia and pars tuberalis and the neurohypophysis that includes the pars nervosa, infundibular stem and median eminence. The pars distalis occupies the major part of the gland $(70 \%)$ where it synthesizes and secretes trophic hormones that control the function of peripheral endocrine glands and other cell types [15].
The pars distalis cells are divided into hormonal (granular) and non-hormonal (agranular) cells, each representing about $50 \%$ of the total cell number. The hormonal cells, also called chromophils, are classified into acidophils and basophils $(40 \%$ and $10 \%$ of the pars distalis cells, respectively) [16]. The acidophils are of two types: somatotrophs secrete growth hormone $(\mathrm{GH})$ and mammotrophs secrete prolactin (PRL). The basophils comprise thyrotrophs secreting thyrotropin-stimulating hormone (TSH), gonadotrophs secreting follicle-stimulating hormone (FSH) and luteinizing hormone ( $\mathrm{LH})$ and corticotrophs secreting mainly adrenocorticotropin (ACTH) and to lesser extent melanotropin (MSH) and lipotropin (LPH) [17].

The non-hormonal cells, also called chromophobes, include the recently degranulated cells, the actively hormone-secreting cells or folliculo-stellate cells (FSCs) which represent 5-10\% of all anterior pituitary cells [18]. FSCs are star-shaped cells that surround colloid-filled follicles representing cellular debris. Their processes interdigitate with the hormonal cells contacting them and the other FSCs via gap junctions [19]. Thus, they were proved to support the endocrine cells and are thought to maintain their functions through paracrine secretion of interleukin-6 (IL-6) and growth factors: vascular endothelial growth factor (VEGF) and basic fibroblast growth factor (bFGF). Moreover, they probably participate in the control of the transport of the hypothalamic stimulatory and inhibitory factors to the pituitary secretory cells and the conveyance of the hormonal products of these cells to the peripheral tissues. The FSCs have phagocytic ability for the cellular debris and apoptotic bodies of the endocrine cells and can act as stem cells for these cells $[14,18]$.

Most of the studies tracked the effect of systemic administration and distribution of NPs in liver, spleen, lung, kidney, heart, and brain after repeated doses $[4,12]$. However, for our knowledge, the distribution and the potential consequences associated with the Au-NPs on the pars distalis of the pituitary gland during their clinical application and drug-delivery have not been examined before despite its major role in the control of endocrine homeostasis. Thus, this work was carried out to explore the histological and the biochemical effects of repeated oral Au-NPs administration on the pars distalis of the pituitary gland (the endocrine regulator) in adult male albino rats with special emphasis on FSCs.

\section{Materials and methods}

Materials. Citrate capped-gold nanoparticles (Au-NPs) was purchased from Nano Tech Egypt for Photo-Electronics $\left(6^{\text {th }}\right.$ 
October City, Egypt) as a purple solution of $200 \mu \mathrm{g} \mathrm{Au}-\mathrm{NPs} / \mathrm{ml}$ of sodium citrate. The following primary rabbit polyclonal antibodies were used: anti- S-100 (Cat. No. ab11428, Abcam, Branford, CT, USA), anti-connexin43 (anti-Cx43) (Cat. No. bs-0651R, Bioss Antibodies Inc., Woburn, MA, USA), anti-Cytochrome-C (anti-Cyt-C) (Cat. No. ab90529, Abcam).

Animals. Thirty-six adult male Wistar albino rats $(\sim 200 \mathrm{~g})$ were used in this study. They were housed in the laboratory animal house unit, Faculty of Medicine, Cairo University, Cairo, Egypt, and treated according to the guidelines granted by the Institutional Animal Care and Use Committee (IACAUC), Cairo University, Cairo, Egypt (Approval No. CU-III-F-48-20). The rats were kept under the same environmental conditions (ordinary rat chow and water ad libitum, $24 \pm 1{ }^{\circ} \mathrm{C}$ and normal light/ /dark cycle) for 48 hours before starting the experiment to acclimatize to the new environmental conditions and relief any kind of stress.

Experimental design. The rats were equally divided into two groups, 18 rats each:

Group I (control group): the animals were subdivided into two subgroups ( 9 rats each): group Ia: received no treatment (control group) and group Ib: each rat received a single oral daily dose of $1 \mathrm{ml}$ sodium citrate via a gastric tube for two weeks (sham-operated group).

Group II (Au-NPs group): each rat was given a daily oral dose of Au-NPs ( $40 \mu \mathrm{g} / \mathrm{kg} /$ day $)$ from the purchased solution in $1 \mathrm{ml}$ sodium citrate, via a gastric tube for two weeks [20].

Citrate capped-gold nanoparticles preparation. Au-NPs were prepared according to previously described methodology [21]. This occurred by citrate reduction of $\mathrm{Au}^{3+}$ ions in chloroauric acid $\left(\mathrm{HAuCl}_{4}\right)$ to neutral citrate capped gold atoms. By the increase in gold atoms formation, the solution came to be supersaturated and the gold atoms were increasingly precipitated in the form of sub-nanometer particles. Filtration of the citrate capped Au-NPs colloidal solution was done through $0.45 \mu \mathrm{m}$ Millipore syringe filters and the filtrate was kept at $\mathrm{pH} 7$ using $\mathrm{NaOH}$ diluted solution $\left(10^{-7} \mathrm{M}\right)$ and then stored at $4^{\circ} \mathrm{C}$.

Ten $\mathrm{ml}$ of a prepared $1 \mathrm{nM}$ of citrate-capped $\mathrm{Au}-\mathrm{NPs}$ in $1 \mathrm{~L}$ of $\mathrm{NaOH}$ solution were centrifuged at $13,500 \mathrm{rpm}$ for $10 \mathrm{~min}$. The resultant pellet was then re-suspended in $1.2 \mathrm{mM}$ sodium citrate to prepare a solution of $200 \mu \mathrm{g} \mathrm{Au}-\mathrm{NPs} / \mathrm{ml}$.

Spectrophotometry and transmission electron microscopy (TEM) were used to identify the Au-NPs. By spectrophotometry, the Au-NPs revealed strong light absorption in the visible region of the optical spectrum with a maximum absorbance at $520 \mathrm{~nm}$ [4]. JEOL JEM-2100 microscope (Jeol, Tokyo, Japan) was utilized at high resolution at $200 \mathrm{kV}$ to clarify the shape and the size of Au-NPs (Fig. 1A, B).

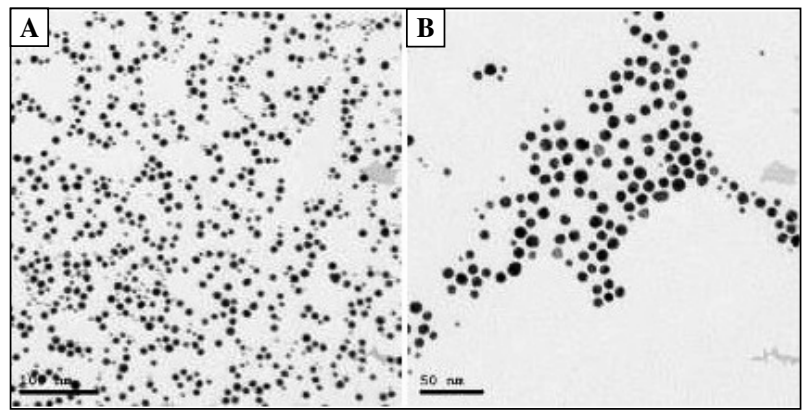

Figure 1 A, B. Ultrahigh magnification of TEM images of citrate capped gold nanoparticles (NanoTech Egypt for Photo-Electronics, Egypt) (Scale bars 100 and $50 \mathrm{~nm}$ ).

Statistical analysis of the Au-NPs size was done by measuring the core diameter of 200 particles from different micrographs at high magnification, mainly at $50000 \times$. The mean size $( \pm \mathrm{SD})$ of the synthesized Au-NPs were $11 \pm 2 \mathrm{~nm}$ spherical particles.

Sample collection. After 2 weeks in the animal house, blood samples were collected from tail veins and delivered to centrifuge tubes to be centrifuged for $20 \mathrm{~min}$. The serum was separated from the samples and stored at $4^{\circ} \mathrm{C}$ for further use.

All rats were euthanized using intraperitoneal injection of ketamine $(90 \mathrm{mg} / \mathrm{kg}) / x y l a z i n e ~(15 \mathrm{mg} / \mathrm{kg})$. Then, the animals of each control group (Ia and Ib) and Au-NPs group were equally divided into 3 sets (i.e. each set had 3 rats from each control subgroup and 6 rats from $\mathrm{Au}-$ NPs group). The rats of the first and the second sets were perfused intracardially by $10 \%$ formol saline while the rats of the third set were perfused by $2.5 \%$ glutaraldehyde at $4^{\circ} \mathrm{C}$. The skulls were opened and the pituitary glands were dissected. The pituitary glands of the $1^{\text {st }}$ set were used for measuring the accumulated Au-NPs and the biochemical investigations, those of the $2^{\text {nd }}$ set were used for the preparation of paraffin blocks and those of the $3^{\text {rd }}$ set were used for the preparation of resin blocks for TEM.

Measurement of Au-NPs accumulation by Inductively Coupled Plasma Mass Spectrometry (ICP-MS). Measurements of the content of Au-NPs in the pituitary glands were done at the National Institute of Laser Enhanced Sciences, Cairo University, Cairo, Egypt, using ICP-MS technique [22]. Concisely, the whole collected wet gland was heated at $50^{\circ} \mathrm{C}$ in $75 \% \mathrm{HNO}_{3}$ overnight (the volume of the acid was 10 times the volume occupied by the gland). Dilution of the digested product (200 times) with deionized water followed by its overnight storage at $50^{\circ} \mathrm{C}$ was done. Filtration using a $0.45 \mu \mathrm{m}$ filter was accomplished before analysis in ICP-MS (Perkin Elmer: Elan 6100, PerkinElmer Inc., Wellesley, MA, USA). 
Biochemical investigations. Serum hormones levels. At the Biochemistry Department, Faculty of Medicine, Cairo University, Cairo, Egypt, prolactin (PRL), LH and FSH were measured in the serum using rat-specific ELISA kits (MBS727546, MBS2509833, and MBS2021901, respectively; MyBioSource, San Diego, CA, USA). Values were expressed as $\mathrm{mlU} / \mathrm{mL}$ and $\mathrm{ng} / \mathrm{mL}$.

Pituitary homogenates and Enzyme-Linked ImmunoSorbent Assay (ELISA). Homogenates of the pituitary glands were prepared in a following way. The whole glands of each group were divided into segments, which were homogenized in $10 \%$ ice-cold phosphate-buffered saline (PBS, $\mathrm{pH} 7.4$ ) for $10 \mathrm{~min}$ in a glass manual homogenizer. The homogenate was centrifuged at $10,000 \mathrm{~g}$ for $20 \mathrm{~min}$ at $4^{\circ} \mathrm{C}$. The resulting supernatant was used for ELISA according to the manufacturer's instructions of each kit data sheet to measure the content of (i) Tumor necrosis factor- $\alpha$ (TNF- $\alpha$ ) and (ii) B cell lymphoma-2 (Bcl-2) using ELISA kits supplied by Abcam (ab100785 \& ab227899, respectively). The content of malondialdehyde (MDA), catalase, and bFGF was measured using ELISA kits supplied by MyBioSource (MBS738685, MBS765803 \& MBS2509327, respectively). Values were expressed per mg protein.

Histological studies. Light microscopic studies. The paraffin blocks of the pituitary glands in the $2^{\text {nd }}$ set of animals were cut in $6 \mu \mathrm{m}$-thick sections and stained with hematoxylin and eosin (H\&E) and by Periodic Acid Schiff's (PAS) reaction [23].

Immunohistochemistry. The immunohistochemical stainings were performed to detect: (i) S-100 protein, a marker for FSCs that appears as a cytoplasmic and/or a nuclear reaction; (ii) Connexin 43 (Cx43), a marker for FSCs gap junctions that appears at the site of connexin43 protein, and (iii) $\mathrm{Cy}$ tochrom-C (Cyt-C), a marker for apoptosis that appears as a cytoplasmic reaction in the apoptotic cells.

Immunostaining using avidin-biotin technique was carried out as described previously [24]. In short, antigen was retrieved by boiling slides for $10 \mathrm{~min}$ in $10 \mathrm{mM}$ citrate buffer pH 6 (Cat. No. 005000, Thermo Fisher Scientific, Waltham, MA, USA). Sections were left to cool for $20 \mathrm{~min}$ at room temperature, then they were incubated overnight with the primary antibodies in a humidity chamber using the following dilutions: 1:50 for anti-S100, 1:200 for anti-Cx43; and $1 \mu \mathrm{g} / \mathrm{ml}$ for anti-Cyt-C. Immunostaining was completed using Ultravision One Detection System (Cat. No. TL-060-HLJ, Thermo Fisher Scientific). Counterstaining was carried out using Lab Vision Mayer's hematoxylin (Cat. No. TA060-MH, Thermo Fisher Scientific). Negative control sections were prepared by the same process after omitting the primary antibodies.
Electron microscopy. The sectioning, staining and examination of the ultrathin sections were carried out at the Electron Microscopy Unit, Faculty of Agriculture, Cairo University, Cairo, Egypt. The pituitary glands of the $3^{\text {rd }}$ set of rats were cut into small fragments $\left(0.5-1.0 \mathrm{~mm}^{3}\right)$, prefixed in $2.5 \%$ glutaraldehyde for $2 \mathrm{~h}$ then post-fixed in $1 \%$ osmium tetroxide in $0.1 \mathrm{M}$ phosphate buffer at $\mathrm{pH}$ 7.4 and left at $4^{\circ} \mathrm{C}$ for $2 \mathrm{~h}$. Dehydration in ascending grade of ethanol then propylene oxide, as a solvent for resin infiltration, were used. The gradual introduction of the liquid resin was followed by embedding in epoxy resin to obtain resin blocks. Ultrathin (60-90 nm) sections were cut using a Leica Ultracut ultramicrotome (Glienicker, Berlin, Germany). They were stained with uranyl acetate followed by lead citrate and examined by TEM JEOL JEM-1400 (Jeol).

FSCs and their processes were digitally colored blue, using Adobe Creative Cloud Photoshop CC 2020 (Adobe Inc., San Jose, CA, USA), for their proper recognition.

Morphometry. Serial non-overlapping fields, at a magnification of $200 \times$, from each group were used to measure the mean area percent $(\%)$ of PAS positive reaction and S-100, Cx43 and Cyt-C immunoreactivity. Leica Qwin-500 LTD-software image analysis computer system (Leica, Cambridge, UK) was used for image analysis.

Statistical analysis. The morphometric and biochemical measurements were expressed as mean \pm standard deviation (SD) and were analyzed with Statistics for Windows SPSS version 21 software (IBM Corp., New York, NY, USA) using $t$-test for independent-samples. The results were considered statistically significant when the P-value was $<0.05$.

\section{Results}

No deaths or abnormal behaviors were observed in any of the experimental animals. Since similar histological and biochemical results were found in the two control subgroups, they were collectively called control group (group I).

\section{Content of Au-NPs in the pituitary}

The ICP-MS revealed complete absence of Au-NPs in the pituitary glands of control group; however, in the Au-NPs group, their mean content was $0.17 \pm 0.02$ $\mathrm{mg} / \mathrm{L}$ of the solution prepared for ICP-MS.

\section{Biochemical results}

Serum hormones levels. Group II revealed a significant decrease in the mean values of serum PRL, LH, $\mathrm{FSH}$, and the tissue Bcl-2 when compared to control group (Table 1). 
Table 1. The serum levels of LH, FSH, PRL, TNF- $\alpha$, Bcl-2, MDA, bFGF and catalase measured by ELISA $($ mean $\pm \mathrm{SD})$

\begin{tabular}{|l|c|c|}
\hline Parameters/Groups & Control & Au-NPs \\
\hline LH $[\mathrm{mIU} / \mathrm{mL}]$ & $19.3 \pm 1.1$ & $10.1 \pm 0.9^{*}$ \\
\hline FSH $[\mathrm{ng} / \mathrm{mL}]$ & $52.4 \pm 3.5$ & $39.8 \pm 1.8^{*}$ \\
\hline PRL $[\mathrm{ng} / \mathrm{mL}]$ & $8.2 \pm 0.9$ & $5 \pm 1^{*}$ \\
\hline TNF- $\alpha$ [pg/mg protein] & $14.1 \pm 1.3$ & $68.7 \pm 3.6^{*}$ \\
\hline Bcl-2 [pg/mg protein] & $192.5 \pm 6.6$ & $101.9 \pm 5.7^{*}$ \\
\hline MDA [nmol/mg protein] & $26.3 \pm 1.4$ & $113.9 \pm 4.2^{*}$ \\
\hline $\begin{array}{l}\text { Catalase }[\mathrm{mlU} / \mathrm{mg} \text { protein] } \\
\text { bFGF }[\mathrm{pg} / \mathrm{mg} \text { protein] }\end{array}$ & $\begin{array}{c}108.2 \pm 3 \\
38.5 \pm 2.1\end{array}$ & $\begin{array}{c}115.4 \pm 2.8 \\
92.7 \pm 2.9^{*}\end{array}$ \\
\hline
\end{tabular}

*Significantly different from the control group, $p<0.05, \mathrm{n}=6$

Pituitary homogenate ELISA results revealed a significant increase in the mean content of TNF- $\alpha$, $\mathrm{MDA}$, and $\mathrm{bFGF}$ and no change in the mean value of catalase versus group I (Table 1).

\section{Morphological changes and cellular apoptosis in the pars distalis of $\mathrm{Au}$-NPs group}

Examination of the H\&E-stained control pituitary sections revealed normal histological architecture where the gland showed pars distalis, pars intermedia and pars nervosa (Fig. 2A). The hypophyseal cleft was present between the pars distalis on one side and the pars intermedia and nervosa on the other side (Fig. 2B).

The pars distalis parenchyma was made of irregular cords of cells with capillaries in-between. These cells include chromophobes or chromophils. The chromophobes were pale polyhedral cells with central rounded vesicular nuclei. The basophils seemed fewer than acidophils and had basophilic cytoplasm and rounded vesicular nuclei whereas the acidophils were more abundant and smaller in size than basophils. They had acidophilic cytoplasm and rounded vesicular nuclei (Fig. 2C).

In the Au-NPs group, the pars distalis H\&E-stained sections revealed structural disorganization and intensive cellular damage (Fig. 2D). Most of the cells were shrunken with deeply eosinophilic cytoplasm. Additionally, the nuclei appeared shrunken, darkly stained and some of them demonstrated chromatin margination or fragmentation (Fig. 2E). Moreover, there were mononuclear inflammatory cell infiltration and dilated congested blood vessels with extra-vascular exudation (Fig. 2F).

\section{Decreased PAS-reactivity in basophils and increased extracellular colloid PAS-reactivity in Au-NPs-treated rats}

There was positive intracellular PAS reaction in the control group sections demonstrating the basophils (Fig. 2G). Moreover, extracellular positive PAS reaction was detected in rounded or oval masses (colloid) between the cells (Fig. 2G). In group II sections, the intracellular reaction was severely diminished while the extracellular reaction became more obvious (Fig. 2H). However, there was no change in the mean area percent of PAS reaction in Au-NPs group in comparison to the control group (Fig. 2I).

\section{Increased proliferation of FSCs in Au-NPs group}

Sections of the pars distalis control group showed S-100 positive immunoreaction in the FSCs and their processes. These cells appeared encircling follicles which were faintly immunoreactive. In addition, their processes extended in-between the surrounding secretory cells (Fig. 3A). Such positive reaction was radically increased in group II with statistically significant increase in its mean area percent as compared to the control rats (Fig. 3B, C).

\section{Increased distribution of gap junctions in the anterior pituitary of $\mathrm{Au}-\mathrm{NPs}$ group}

The $\mathrm{Cx} 43$ positive immunoreactivity detected in the control sections (Fig. 3D) became widely spread in the sections of Au-NPs treated rats with significantly increase mean area percent (Fig. 3E, F).

\section{Increased apoptosis in adenohypohysis of rats treated with $\mathrm{Au}-\mathrm{NPs}$}

Cells with Cyt-C positive immunoreactivity were few in the control sections (Fig. 3G). However, in Au-NPs sections, Cyt-C immunoreaction was abundantly widespread with statistically significant increase in its mean area percent in Au-NPs group versus the control group (Figs. 3H, I).

\section{Increased immunoreactivity of connexin 43 in $\mathrm{Au}-\mathrm{NPs}$ group}

The $\mathrm{Cx} 43$ positive immunoreaction detected in the control sections (Fig. 3D) became widely spread in the sections of part distalis of Au-NPs treated rats with a statistically significant increased mean area percent (Fig. 3E, F).

Increased number of apoptotic cells in Au-NPs group Cells with Cyt-C immunoreactivity were few in the anterior pituitary of control rats (Fig. 3G). However, in rats treated with Au-NPs sections, the Cyt-c immunereaction was abundantly widespread with 

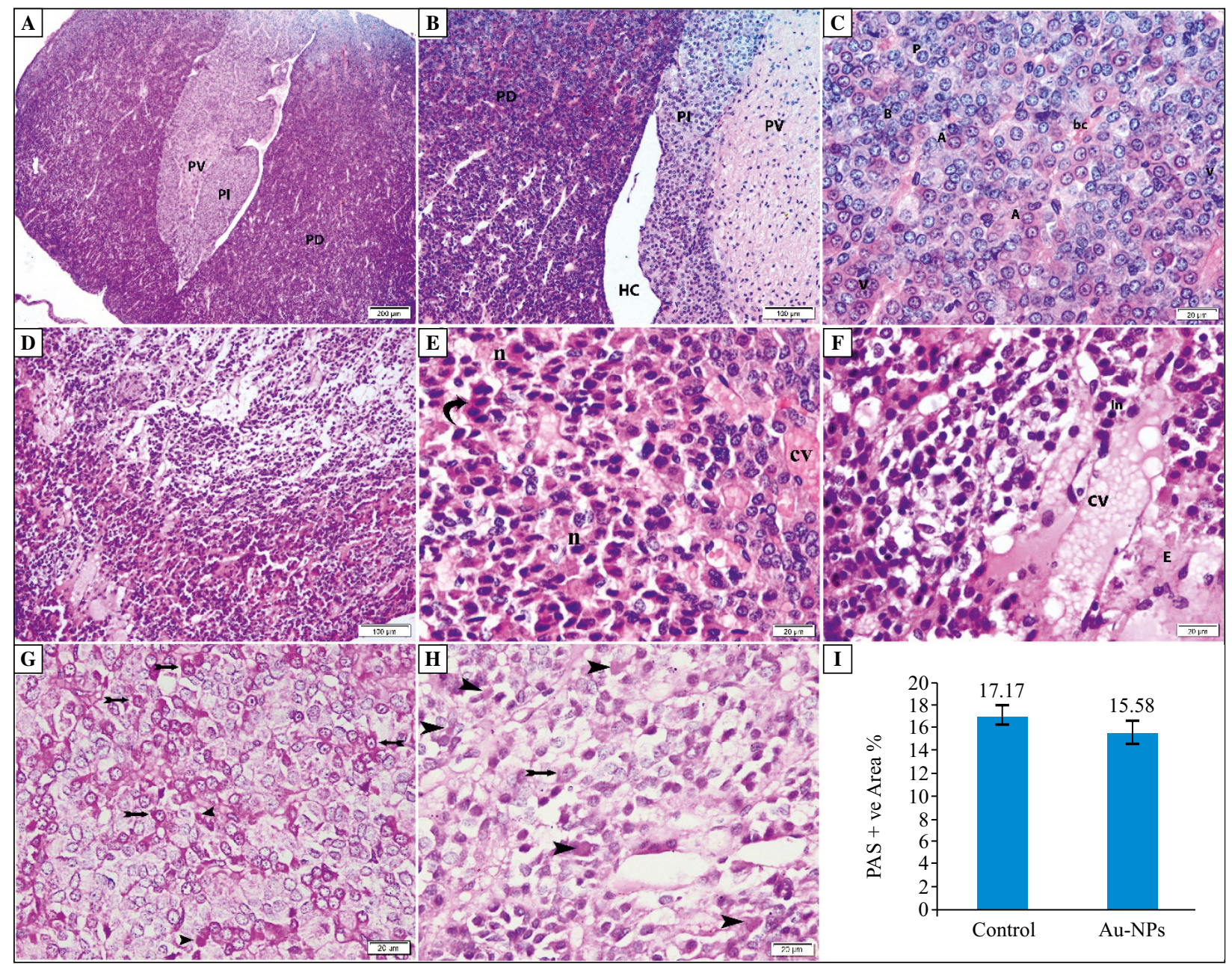

Figure 2. Photomicrographs of H\&E stained pituitary sections. The pituitary glands in the control group (A, B, C) presented with the normal tissue architecture demonstrating pars distalis (PD) on the left and right sides and pars intermedia (PI) \& pars nervosa (PV) in the middle (A), and at the higher magnification the hypophyseal cleft (HC) between PD and PI (B). At (C) the pars distalis shows blood capillaries (BC) between cellular cords of chromophobes (P), acidophils (A) and basophils (B). All the cell types reveal rounded vesicular nuclei (v). The pituitary of rats in the Au-NP group (D, E, F) demonstrates disturbed architecture (D). In (E) there are visible shrunken cells with deeply eosinophilic cytoplasm (curved arrow) as well as cells with shrunken nuclei (n). In (F) inflammatory cell infiltration (In) and dilated congested vein (cv) with extra-vascular exudation (E) are noticed. Photomicrographs of PAS reaction in the pars distalis are shown in (G) and $(\mathrm{H})$. In the control group $(\mathrm{G})$, numerous positive intracellular reaction products (bifid arrow) are present in the basophils and extracellular reaction (arrowheads) are visible in the colloid. The cells of pars distalis of the Au-NP group (H) show diminished intracellular reaction (bifid arrow) and increment of the extracellular reaction (arrowhead). (I) The mean area percent of PAS reaction in pars distalis of the pituitary glands. Data are presented as mean \pm SD ( $n=6$ for each group). Magnifications: (A) 40×; (B, D) 100×; (C, E, F, G, H) 400×.

statistically significant increased mean area percent versus the control group (Figs. 3H, I).

\section{Ultrastructure the of the pars distalis cells of control rats}

Control group sections (Fig. 4A-F) revealed the presence of secretory and non-secretory cells presenting euchromatic nuclei with prominent nucleoli. Mammotrophs contained relatively large secretory granules of variable size (Fig. 4B). The somatotrophs (Figs. $4 \mathrm{C}$ and $4 \mathrm{D}$ ) showed cisternae of rough endoplasmic reticulum (rER), multiple mitochondria and relatively abundant large scattered dense secretory granules. The corticotrophs (Fig. 4E) appeared as low electron dense stellate-shaped cells with the cytoplasm demonstrating few rER cisternae, mitochondria and small granules alongside the cell membrane. Furthermore, the gonadotrophs (Fig. 4E) were shown with rounded secretory granules of variable size and density located at the pole of the cells. Thyrotrophs (Fig. 4F) displayed $\mathrm{rER}$, mitochondria and the smallest secretory granules among all secretory cells. 


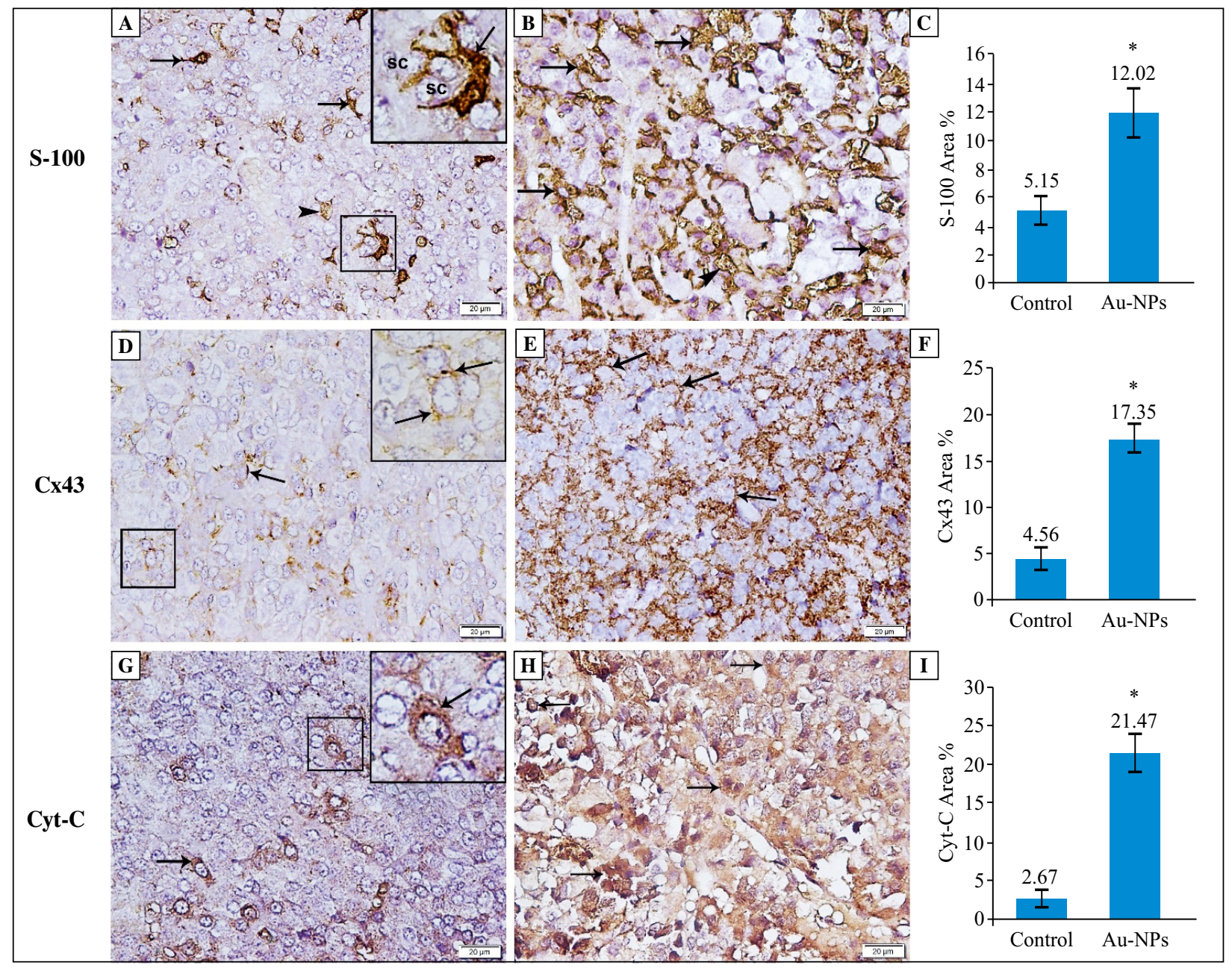

Figure 3. Photomicrographs of immunohistochemistry in the pars distalis sections for S-100, Cx43 and Cyt-C. Anti-S-100 immunohistochemistry: The pituitary glands of rats in the control group (A) show some cells demonstrating positive immunoreaction (arrow) in the cytoplasm, the nuclei and the processes of FSCs which surround cell follicles. A faint positive immunoreaction is noted in the follicular colloid (arrowhead). The right up inset: a higher magnification of the boxed area illustrates a follicle, FSCs (arrow) and their processes extended between the secretory cells (sc). The pituitary glands of rats in the Au-NP group (B) reveal marked increase in the positive FSCs (arrow) and colloid (arrowhead) immunoreaction. Anti-CX-43 immunohistochemistry: The control group (D) displays some FSCs and their processes illustrate positive immunoreaction (arrow). The right inset: a higher magnification of the boxed area illustrates the reaction in the FSCs processes in-between the secretory cells. The Au-NP group (E) shows widely spread positive immunoreaction (arrow). Anti-Cyt-c immunohistochemistry: The control group (G) shows few cells with positive cytoplasmic immunoreaction (arrow). The upper right inset: a higher magnification of the boxed area illustrating the cytoplasmic reaction (arrow) in a hormonal cell. The Au-NP group (H) displays abundant positive immunoreaction (arrow). (C, F, I) The mean area percent of S-100, Cx43 and Cyt-C immunoreactivity, respectively. Data are presented as mean $\pm \mathrm{SD}(\mathrm{n}=6$, for each group). *significantly different from control, $p<0.05$. Magnifications: A, B, D, E, G and H: 400×; Insets: $1000 \times$.

The FSCs in the control group (Figs. 4A-C) were demonstrated as star-shaped cells with ovoid euchromatic nuclei, non-granular cytoplasm with electron-dense bodies (assumed to be lysosomes). They lined small follicles. The lumens of these follicles were surrounded by junctional complexes (Fig. 4D). These follicular lumens were filled with electron-lucent colloid. The processes of these cells were stretched between the secretory cells and extended to the blood capillaries. Gap junctions were visualized between the FSCs and between them and the secretory cells (Fig. 4D and 4F).

\section{Ultrastructural degenerative changes in the secretory cells of pars distalis in rats treated with Au-NPs are accompanied by increased activity of FSCs}

In the pars distalis of rats treated with AU-NPs (Figs. $5 \mathrm{~A}-\mathrm{F}$ ), it was difficult to differentiate between various types of secretory cells as they all revealed features 

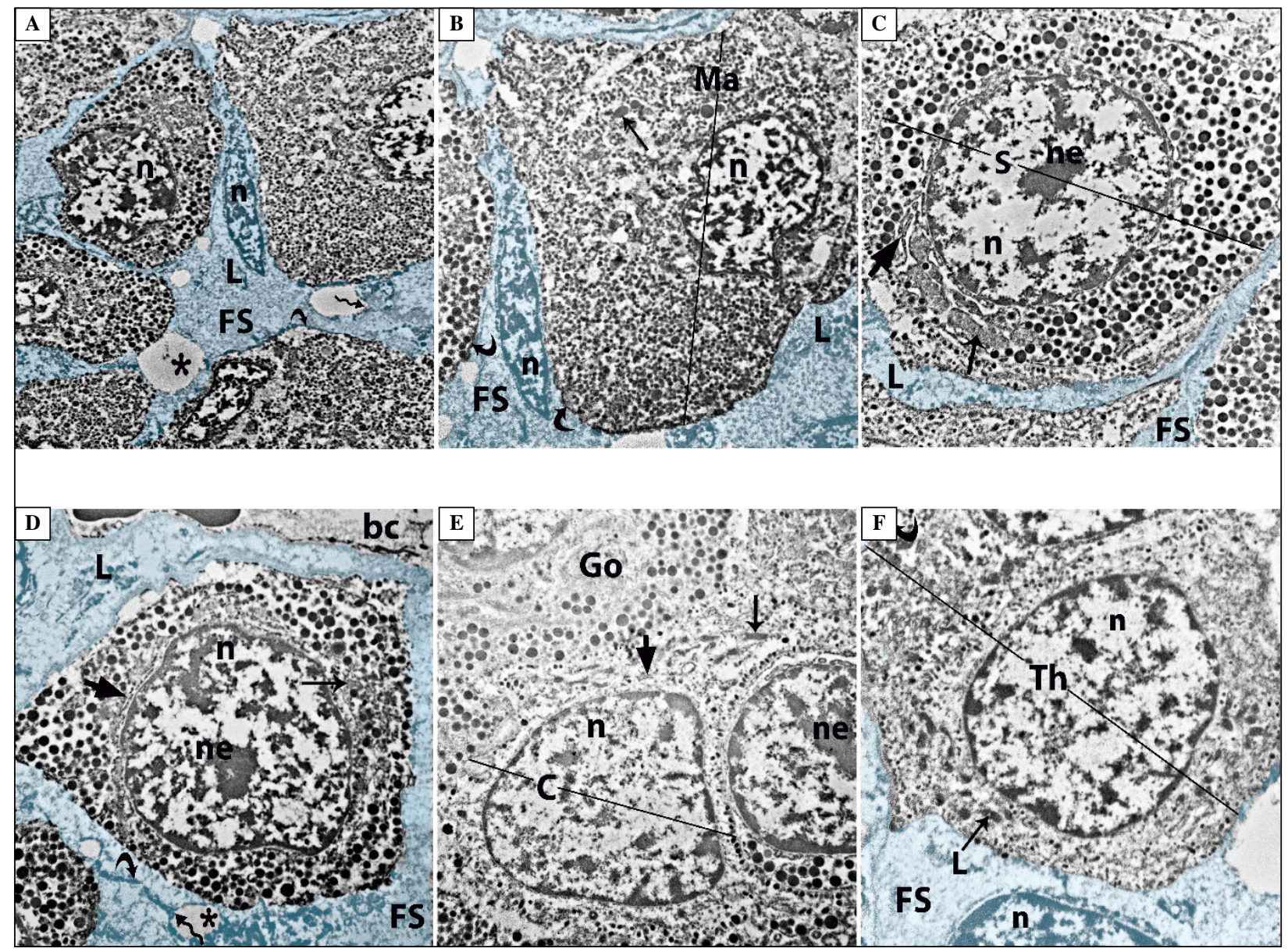

Figure 4. TEM photomicrographs of pars distalis in the rat pituitary glands of the control group. In (A) normal ultrastructure of endocrine cells and blue-labeled FSCs (FS) are noted. In (B) mammotrophs (Ma), illustrate abundant variable sized granules. In (C and D) somatotrophs (S) display abundant large dense granules. In (E) gonadotrophs (Go) show rounded granules of variable size and density mainly at the pole of the cell, while corticotrophs (C) with the fewest granules that are small and peripherally located immediately under the plasmalemma. In (F) thyrotrophs (Th) show many peripheral small granules. All secretory cells reveal euchromatic nuclei (n), prominent nucleoli (ne), rER (short arrow) and mitochondria (arrow). FSCs (FS) are visualized with euchromatic nuclei (n), and lysosomes (L). They line follicles filled with colloid (*) and surrounded by junctional complexes (wavy arrow). Their processes are stretched between the secretory cells and extend to the blood capillaries (bc). Gap junctions (curved arrow) are noted between FSCs and between them and the secretory cells. Magnifications: A: 5000×; B: $6000 \times$; C, D and E: $8000 \times$; F: $1000 \times$; (B) is a higher magnification of (A).

of cellular damage. The cells appeared fused with rarified vacuolated cytoplasm, swollen degenerated mitochondria with ruptured cristae, dilated disrupted rER and reduced number of secretory granules. In addition, the nuclei revealed signs of apoptosis such as nuclear irregularity, shrunken dense nuclei, multiple large chromatin clumps and chromatin margination.

On the contrary, the FSCs (Figs. 5A-G) demonstrated apparently normal ultrastructure with multiple electron-dense particles within the colloid. Additionally, FSCs contained multiple cytoplasmic electron-dense bodies (lysosomes), multiple mitochondria and vesicles filled with colloid material.

\section{Discussion}

The current work aimed at investigating the histological and biochemical influences of repeated oral intake of small-sized $(11 \pm 2 \mathrm{~nm})$ Au-NPs on the pars distalis of the pituitary gland of adult male albino rats, with special reference to their effects on FSCs.

In this study, small-sized Au-NPs were chosen because it was demonstrated that nanoparticles' diagnostic and therapeutic features such as plasma half-life [25], uptake by the cells [26] and tumor infiltration [27], are affected by their sizes. It has been assumed that for effective biological effects of NPs their size 

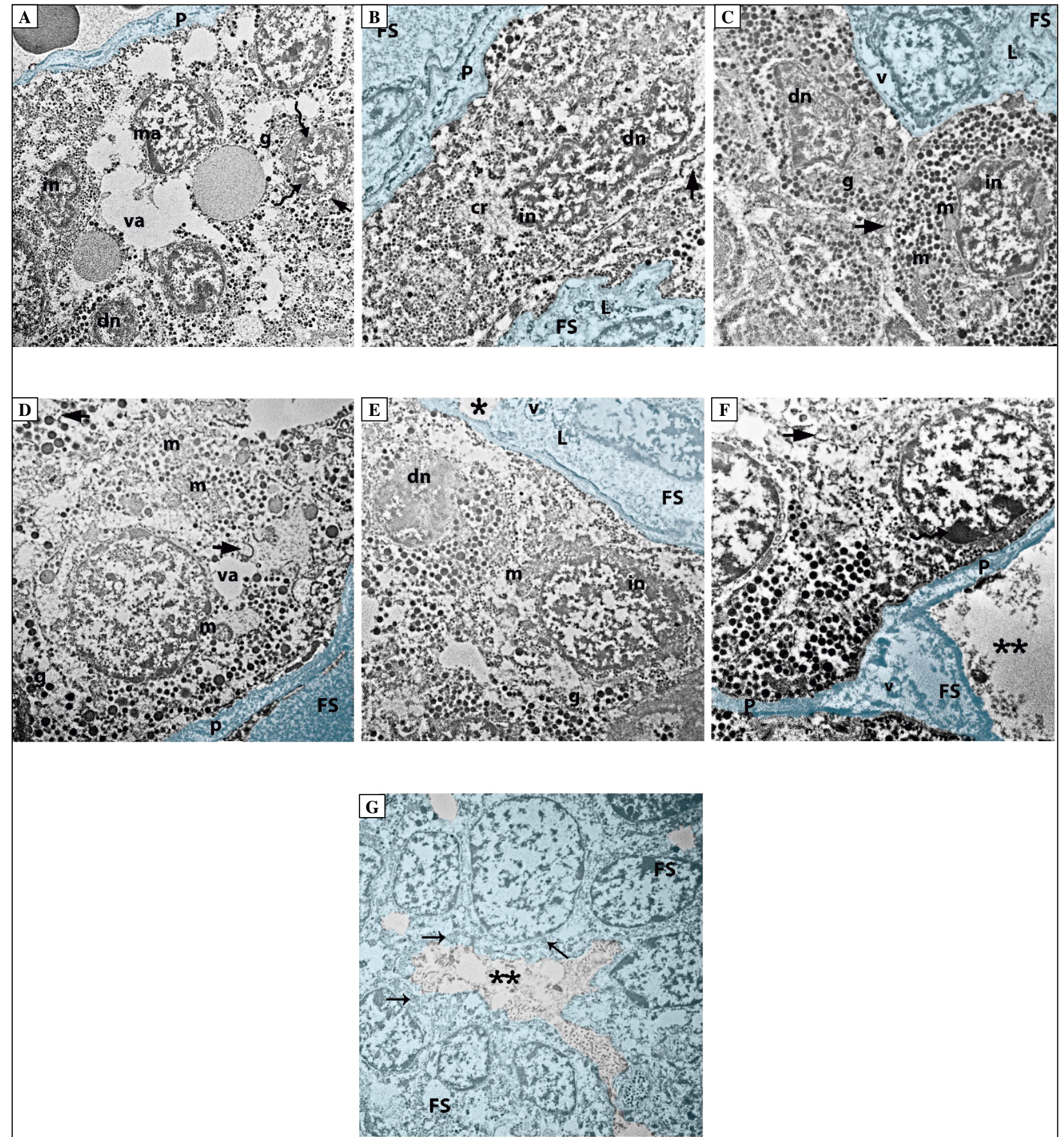

Figure 5. TEM photomicrographs of pars distalis in the rat pituitary glands of the Au-NP group. EM photographs A-D show marked degeneration of different endocrine cells illustrating fused cells with cytoplasmic vacuolations (va) and rarefication $(\mathrm{Cr})$ dilated disrupted rER (short arrow), swollen mitochondria with ruptured cristae $(\mathrm{m})$ and few secretory granules (g). The nuclei are either irregular (in), shrunken dense (dn), with multiple chromatin clumps (wavy arrow) or chromatin margination (ma). The FSCs (FS) appear almost normal and contain multiple lysosomes (L) and colloid-filled vesicles (v). (A-F) The FSCs' processes (P) embrace the hormonal cells and/or the colloid materials $\left(^{*}\right)$. The large-sized colloid (**) display multiple electron-dense particles. (G) A group of FSCs (FS) surrounding large-sized colloid (**) and they display multiple mitochondria (arrow) in their cytoplasm. Magnifications: A: 4000×; B, C and E: 6000×; D and F: 8000×; G: 5000×. 
has to range between $10-200 \mathrm{~nm}$ since NPs smaller than $10 \mathrm{~nm}$ can be filtered by the kidneys and NPs larger than $200 \mathrm{~nm}$ could activate the immune system resulting in their elimination from blood [28]. So, the optimum size was recognized to be $50 \mathrm{~nm}$ [26] but the size of 10-20 nm adds more therapeutic benefits like the tumor penetration ability [27]. Additionally, male rats were used to avoid the changes that occur in the density of the somatotrophs and the mammotrophs in females due to the trans-differentiation between them [29].

In the current work, the rats which received orally Au-NPs for 2 weeks were found to accumulate $\mathrm{Au}-\mathrm{NPs}$ in the pituitary gland detected by ICP-MS. This is concomitant with formerly reported results where Au-NPs were accumulated in different mice organs following single and repeated intravenous administrations, repeated intraperitoneal injections and oral intake [12]. In rodents, such deposition could be explained by the distribution of Au-NPs throughout the body by blood, with the liver and the spleen (mononuclear phagocytic system) being the first organs to show Au-NPs accumulation, followed by the lungs [30]. Once the nanoparticles reached the systemic circulation, they were distributed via blood to all other organs including kidneys [31]. Additionally, $20 \mathrm{~nm}$-sized Au-NPs can cross the blood-retina barrier resulting in their deposition in the retina [32].

In various organs, Au-NPs were taken up by the cells mainly through clathrin-mediated endocytosis [33]. This occurs via two stages; the first one is a rapid phase that lasts for $6 \mathrm{~h}$ where the Au-NPs are free and easily taken-up by the cells and the second one is a plateau stage where the particles are conjugated with serum proteins forming more stable Au-NPs/ /protein complexes [34]. Such cellular uptake occurred deoebdent on Au-NPs size where the smaller ones $(10 \mathrm{~nm})$ were more widely deposited in the organs than larger ones $(50 \mathrm{~nm})$ [35].

The main finding of our study was the demonstration that the deposition of Au-NPs in the pars distalis of young adult male rats resulted in its disorganization and cellular damage. Our study adds important data to the research on the distribution of gold nanoparticles in other organs of rat [31] and mouse [30]. In the present study we present novel findings indicating deterioration of the histomorphology of the adenohypohysis as a result of the repeated Au-NPs treatment of male Wistar rats. We also showed that the ultrastructural changes induced by Au-NPs administration resulted in functional damage since the serum concentration of FSH, LH and PRL was reduced in the rats treated with gold nanoparticles. One explanation of such a damaging effect of Au-NPS may be related to the oxidative stress as a result of the production of high levels of reactive oxygen species (ROS) [36].

In the present study, tendency to increased catalase level, a key antioxidant enzyme, was noted in $\mathrm{Au}-\mathrm{NPs}$ rats versus the control rats. Although daily oral administration of ( 5 and $10 \mathrm{mg} / \mathrm{kg}$ ) Au-NPs in rats for 3 weeks increased the production of antioxidants, this increase was not statistically significant [31]. In this previous study [31], the antioxidant level was not enough to compensate for the increased ROS leading to imbalance of the redox system [37]. Besides, it was proved that intraperitoneal injection of $20 \mathrm{~nm}$ sized nanoparticles to rats for 3 days reduced the activity of the antioxidant, reduced glutathione peroxidase [38]. This explanation is similar to that proposed by Elbakary et al. to explain lung tissue damage induced by Au-NPs [20].

The high ROS levels lead to DNA damage, protein oxidation and lipid peroxidation [37]. The release of lipid peroxidation products such as MDA and 4-hydroxy-2-nonenal (4-HNE) induces inflammation and apoptotic cell death [39]. This was enforced in the current work by the significant increase in the mean level of MDA in Au-NPs rats as compared to the control rats. Further support came from the presence of inflammatory signs (congestion and dilatation of the blood vessels, extra-vascular exudate and inflammatory cell infiltration) and evidently increased apoptosis expressed in highly increased relative area of Cyt-c immunoreactivity.

These inflammatory signs were previously reported in the lung tissue following Au-NPs administration. Besides, prominent population of Kupffer cells was demonstrated in the liver for more phagocytic activity and nanoparticles elimination [31]. Au-PNs have been shown to induce the release of the pro-inflammatory cytokines, as a sequel of nanoparticles-induced ROS production and oxidative stress where interleukin (IL)- $1 \alpha$ and TNF- $\alpha$ were detected in mice brain following 'nanoparticles' administration [38]. Additionally, other cytokines induced neutrophil chemoattractant and macrophage inflammatory protein- $1 \alpha$ were reported to recruit neutrophils and macrophages to engulf the Au-NPs deposited in the lungs [40]. Such inflammatory reaction explanation was supported in the current study by the significant increase in the serum level of TNF- $\alpha$ in Au-NPs rats as compared to the control rats.

Prolonged inflammation leads to the release of more ROS, more cellular damage and apoptotic cell death [20]. In the adenohypophyseal sections of AU-NPs-treated rats, the detected cellular death was presumed to be due to mitochondrial (intrinsic) pathway of apoptosis, as it resulted from cellular 
stresses (oxidative and inflammatory) [31]. These stresses ensue consequently production of ROS and lipid peroxidation leading to mitochondrial dysfunction [39]. Additionally, it was reported in vitro that Au-NPs overexpress Bax (pro-apoptotic protein) that forms heterodimer with Bcl-2 (anti-apoptotic protein) [41]. This successively results into release of mitochondrial Cyt-c (pro-apoptotic protein) [41] and inevitable apoptotic cell death through increased expression of caspase-3 [31].

Such assumption was enforced by the data presented in this study through the appearance of the mitochondrial degeneration signs in ultrathin sections and the significant increase in the mean area \% of Cyt-c immunoreactivity in Au-NPs group versus the control group. Further reinforcement came from the significant decrease in the level of Bcl-2 in the pars distalis homogenates of group II compared to group I. In the same way, other study [42] stated that accumulated Au-NPs provoke a significant increase in the mRNA expression of Bax, P53, caspase-3 and caspase-9. This, in turn, suggests the intrinsic pathway of apoptosis.

Cellular damage displayed in the pars distalis of group II was furtherly reinforced by the significant decrease in the serum levels of PRL secreted by acidophils, and FSH and LH secreted by basophils. Moreover, there was diminished intracellular PAS positive reaction that indicated reduced basophils content. In the same way, other study denoted decreased GH immunoexpression following cellular apoptosis induced by oral malathion [17].

Interestingly, Au-NPs can cross the blood brain barrier and accumulate in the brain [43]. There, they can induce apoptosis of neurons of the cerebral cortex and the hippocampus [4]. By the same token, they could induce apoptosis in the hypothalamus and their secretory cells. This was supported previously $[44,45]$ by reporting the negative effect of nanoparticles on the ovarian and testicular functions via acting on the hypothalamic-pituitary-gonadal axis.

On the contrary to the secretory cells of the pars distalis, FSCs were shown in Au-NPs-treated rats to be intact and probably proliferated. This was supported by the increase in the mean area percent of the S-100 immunoreactivity in this group versus the control group. This could be explained by the fact that FSCs are considered as the stem cells to the pars distalis endocrine cells [46]. Additionally, they are believed to be their nursing cells via their processes that extend to the blood capillaries and are localized between endocrine cells [47]. Moreover, the gap junctions present between FSCs and between them and the endocrine cells allow rapid spread of the signals and the trophic factors secreted by FSCs to the other FSCs and the endocrine cells which they support, controlling their secretion and promoting their proliferation [48]. Thus, the significant increase in the mean area percent of Cx43 immunoreactivity in Au-NPs rats as compared with the control rats ensured the nursing potential of FSCs.

One of these trophic growth factors is bFGF that is a potent angiogenic factor in the anterior pituitary and it has a paracrine action promoting cell proliferation and differentiation and autocrine action that increases its own secretion. Besides, it increases the gap junctions between FSCs and between FSCs and endocrine cells [48]. In the adenohypophysis it is secreted mainly by FSCs [49]. The significant increase of its serum level in group II was suggested to be due to its augmented secretion by FSCs.

Moreover, FSCs are supposed to be phagocytic cells that engulf the apoptotic pars distalis cells, degrade them within their lysosomes and secrete the residual cellular debris into the colloid in the middle of FSCs clusters [50]. Since the apoptotic cell death was documented in Au-NPs-treated rats to be more intense than in the control rats, the phagocytic capability of FSCs was assumed to be augmented. This was supported by the presence of numerous electron-dense lysosomes and electron-dense particles within the colloid. Further support came from the enlarged colloid size detected in ultrathin sections and the increased extracellular positive PAS reaction. Such increase in this PAS reaction product was identified to probably compensate for its intracellular decrease in basophils due to their apoptosis.

In summary, we demonstrated that in rat repetitive oral administration of small-sized gold nanoparticles resulted in their deposition in the pituitary gland with subsequent degeneration of endocrine cells together with biochemical and functional alterations. However, FSCs proliferated and displayed increased growth factors production, as bFGF. This proliferation could be suggested to remove cell degeneration wastes and to support the endocrine cells via paracrine secretions of these growth factors.

\section{Conflict of interest}

All authors declare no conflict of interest.

\section{References}

1. Jeevanandam J, Barhoum A, Chan YS, et al. Review on nanoparticles and nanostructured materials: history, sources, toxicity and regulations. Beilstein J Nanotechnol. 2018; 9: 1050-1074, doi: 10.3762/bjnano.9.98, indexed in Pubmed: 29719757.

2. Buzea C, Pacheco II, Robbie K. Nanomaterials and nanoparticles: sources and toxicity. Biointerphases. 2007; 2(4): MR17-MR71, doi: 10.1116/1.2815690, indexed in Pubmed: 20419892. 
3. Wicki A, Witzigmann D, Balasubramanian V, et al. Nanomedicine in cancer therapy: challenges, opportunities, and clinical applications. J Control Release. 2015; 200: 138-157, doi: 10.1016/j.jconrel.2014.12.030, indexed in Pubmed: 25545217.

4. El-Drieny EA, Sarhan NI, Bayomy NA, et al. Histological and immunohistochemical study of the effect of gold nanoparticles on the brain of adult male albino rat. J Microsc Ultrastruct. 2015; 3(4): 181-190, doi: 10.1016/j.jmau.2015.05.001, indexed in Pubmed: 30023198.

5. Versiani A, Andrade L, Martins E, et al. Gold nanoparticles and their applications in biomedicine. Future Virol. 2016; 11(4): 293-309, doi: 10.2217/fvl-2015-0010.

6. Chow EKH, Ho D. Cancer nanomedicine: from drug delivery to imaging. Sci Transl Med. 2013; 5(216): 216rv4, doi: 10.1126/scitranslmed.3005872, indexed in Pubmed: 24353161.

7. Lal S, Clare SE, Halas NJ. Nanoshell-enabled photothermal cancer therapy: impending clinical impact. Acc Chem Res. 2008; 41(12): 1842-1851, doi: 10.1021/ar800150g, indexed in Pubmed: 19053240.

8. Luo P, Stutzenberger F. Nanotechnology in the detection and control of microorganisms. Adv Appl Microbiol. 2008: 145-181, doi: 10.1016/s0065-2164(07)00004-4.

9. Marques Neto LM, Kipnis A, Junqueira-Kipnis AP. Role of Metallic Nanoparticles in Vaccinology: Implications for Infectious Disease Vaccine Development. Front Immunol. 2017; 8: 239, doi: 10.3389/fimmu.2017.00239, indexed in $\mathrm{Pu}-$ bmed: 28337198.

10. Pissuwan D, Niidome T, Cortie MB. The forthcoming applications of gold nanoparticles in drug and gene delivery systems. J Control Release. 2011; 149(1): 65-71, doi: 10.1016/j. jconrel.2009.12.006, indexed in Pubmed: 20004222.

11. Skirtach AG, Mu oz Javier A, Kreft O, et al. Laser-induced release of encapsulated materials inside living cells. Angew Chem Int Ed Engl. 2006; 45(28): 4612-4617, doi: 10.1002/ anie.200504599, indexed in Pubmed: 16791887.

12. Lasagna-Reeves C, Gonzalez-Romero D, Barria MA, et al. Bioaccumulation and toxicity of gold nanoparticles after repeated administration in mice. Biochem Biophys Res Commun. 2010; 393(4): 649-655, doi: 10.1016/j.bbrc.2010.02.046, indexed in Pubmed: 20153731.

13. Prades R, Guerrero S, Araya E, et al. Delivery of gold nanoparticles to the brain by conjugation with a peptide that recognizes the transferrin receptor. Biomaterials. 2012; 33(29): 7194-7205, doi: 10.1016/j.biomaterials.2012.06.063, indexed in Pubmed: 22795856.

14. Perez-Castro C, Renner U, Haedo MR, et al. Cellular and molecular specificity of pituitary gland physiology. Physiol Rev. 2012; 92(1): 1-38, doi: 10.1152/physrev.00003.2011, indexed in Pubmed: 22298650.

15. Yeung CM, Chan CB, Leung PS, et al. Cells of the anterior pituitary. Int J Biochem Cell Biol. 2006; 38(9): 1441-1449, doi: 10.1016/j.biocel.2006.02.012, indexed in Pubmed: 16621669.

16. Haschek W, Rousseaux C, Wallig M. Endocrine System. Fundamentals Toxicol Pathol. 2010: 513-551, doi: 10.1016/ b978-0-12-370469-6.00017-9.

17. El-Kordy E, Mubarak HED, Makhlouf M, et al. Effect of malathion on pars distalis of the pituitary gland and the possible protective role of vitamin $\mathrm{C}$ in adult female albino rats. Egyptian J Histol. 2014; 37(3): 453-463, doi: 10.1097/01. ehx.0000452052.09124.28.

18. Pires M. Update on pituitary folliculo-stellate cells. Int Arch Endocrinol Clin Res. 2016; 2(1), doi: 10.23937/2572407x.1510006.

19. Le Tissier PR, Hodson DJ, Lafont C, et al. Anterior pituitary cell networks. Front Neuroendocrinol. 2012; 33(3)
252-266, doi: 10.1016/j.yfrne.2012.08.002, indexed in Pubmed: 22981652.

20. Elbakary R, Okasha E, Ragab A, et al. Histological effects of gold nanoparticles on lung tissue of adult male albino rats. J Microsc Ultrastruct. 2018; 6(2): 116-122, doi: 10.4103/ JMAU. JMAU_25_18, indexed in Pubmed: 30221136.

21. Lévy R, Thanh NTK, Doty RC, et al. Rational and combinatorial design of peptide capping ligands for gold nanoparticles. J Am Chem Soc. 2004; 126(32): 10076-10084, doi: 10.1021/ ja0487269, indexed in Pubmed: 15303884.

22. Barathmanikanth S, Kalishwaralal K, Sriram M, et al. Anti-oxidant effect of gold nanoparticles restrains hyperglycemic conditions in diabetic mice. J Nanobiotechnology. 2010; 8: 16, doi: 10.1186/1477-3155-8-16, indexed in Pubmed: 20630072.

23. Kiernan J. Histological and histochemical methods: Theory and practice. New York: Arnold publisher; 2001.

24. Salama NM, Zaghlol SS, Mohamed HH, et al. Suppression of the inflammation and fibrosis in Asherman syndrome rat model by mesenchymal stem cells: histological and immunohistochemical studies. Folia Histochem Cytobiol. 2020; 58(3): 208-218, doi: 10.5603/FHC.a2020.0024, indexed in Pubmed: 32996119.

25. Faraji AH, Wipf P. Nanoparticles in cellular drug delivery. Bioorg Med Chem. 2009; 17(8): 2950-2962, doi: 10.1016/j. bmc.2009.02.043, indexed in Pubmed: 19299149.

26. Huang J, Bu L, Xie J, et al. Effects of nanoparticle size on cellular uptake and liver MRI with polyvinylpyrrolidone-coated iron oxide nanoparticles. ACS Nano. 2010; 4(12): 7151-7160, doi: 10.1021/nn101643u, indexed in Pubmed: 21043459.

27. Chauhan VP, Stylianopoulos T, Martin JD, et al. Normalization of tumour blood vessels improves the delivery of nanomedicines in a size-dependent manner. Nat Nanotechnol. 2012; 7(6): 383-388, doi: 10.1038/nnano.2012.45, indexed in Pubmed: 22484912.

28. de Barros AB, Tsourkas A, Saboury B, et al. Emerging role of radiolabeled nanoparticles as an effective diagnostic technique. EJNMMI Res. 2012; 2(1): 39, doi: 10.1186/2191-219X2-39, indexed in Pubmed: 22809406.

29. Porter TE, Wiles CD, Frawley LS. Evidence for bidirectional interconversion of mammotropes and somatotropes: rapid reversion of acidophilic cell types to pregestational proportions after weaning. Endocrinology. 1991; 129(3): 1215-1220, doi: 10.1210/endo-129-3-1215, indexed in Pubmed: 1874167.

30. Yang L, Kuang H, Zhang W, et al. Comparisons of the biodistribution and toxicological examinations after repeated intravenous administration of silver and gold nanoparticles in mice. Sci Rep. 2017; 7(1): 3303, doi: 10.1038/s41598-01703015-1, indexed in Pubmed: 28607366.

31. Aravinthan A, Kamala-Kannan S, Govarthanan M, et al. Accumulation of biosynthesized gold nanoparticles and its impact on various organs of Sprague Dawley rats: a systematic study. Toxicol Res (Camb). 2016; 5(6): 1530-1538, doi: 10.1039/c6tx00202a, indexed in Pubmed: 30090454.

32. Kim JH, Kim JH, Kim KW, et al. Intravenously administered gold nanoparticles pass through the blood-retinal barrier depending on the particle size, and induce no retinal toxicity. Nanotechnology. 2009; 20(50): 505101, doi: 10.1088/09574484/20/50/505101, indexed in Pubmed: 19923650.

33. Kreyling WG, Semmler-Behnke M, Möller W. Ultrafine particle-lung interactions: does size matter? J Aerosol Med. 2006; 19(1): 74-83, doi: 10.1089/jam.2006.19.74, indexed in Pubmed: 16551218.

34. Chithrani BD, Ghazani AA, Chan WCW. Determining the size and shape dependence of gold nanoparticle uptake into mammalian cells. Nano Lett. 2006; 6(4): 662-668, doi: 10.1021/n1052396o, indexed in Pubmed: 16608261. 
35. De Jong WH, Hagens WI, Krystek P, et al. Particle size-dependent organ distribution of gold nanoparticles after intravenous administration. Biomaterials. 2008; 29(12): 1912-1919, doi: 10.1016/j.biomaterials.2007.12.037, indexed in Pubmed: 18242692 .

36. Dykman L, Khlebtsov N. Immunological properties of gold nanoparticles. Chem Sci. 2017; 8(3): 1719-1735, doi: 10.1039/ c6sc03631g, indexed in Pubmed: 28451297.

37. Liou GY, Storz P. Detecting reactive oxygen species by immunohistochemistry. Methods Mol Biol. 2015; 1292: 97-104, doi: 10.1007/978-1-4939-2522-3_7, indexed in Pubmed: 25804750.

38. Siddiqi NJ, Abdelhalim MA, El-Ansary AK, et al. Identification of potential biomarkers of gold nanoparticle toxicity in rat brains. J Neuroinflammation. 2012; 9: 123, doi: 10.1186/17422094-9-123, indexed in Pubmed: 22691312.

39. Breitzig M, Bhimineni C, Lockey R, et al. 4-Hydroxy-2-nonenal: a critical target in oxidative stress? Am J Physiol Cell Physiol. 2016; 311(4): C537-C543, doi: 10.1152/ajpcell.00101.2016, indexed in Pubmed: 27385721.

40. Morimoto Y, Izumi H, Kuroda E. Significance of persistent inflammation in respiratory disorders induced by nanoparticles. J Immunol Res. 2014; 2014: 962871, doi: 10.1155/2014/962871, indexed in Pubmed: 25097864.

41. Liu M, Gu X, Zhang Ke, et al. Gold nanoparticles trigger apoptosis and necrosis in lung cancer cells with low intracellular glutathione. J Nanopart Res. 2013; 15(8), doi: 10.1007/ s11051-013-1745-8.

42. Noël C, Simard JC, Girard D. Gold nanoparticles induce apoptosis, endoplasmic reticulum stress events and cleavage of cytoskeletal proteins in human neutrophils. Toxicol In Vitro. 2016; 31: 12-22, doi: 10.1016/j.tiv.2015.11.003, indexed in Pubmed: 26551149.

43. Etame AB, Diaz RJ, O'Reilly MA, et al. Enhanced delivery of gold nanoparticles with therapeutic potential into the brain using MRI-guided focused ultrasound. Nanomedicine. 2012;
8(7): 1133-1142, doi: 10.1016/j.nano.2012.02.003, indexed in Pubmed: 22349099.

44. Hou CC, Zhu JQ. Nanoparticles and female reproductive system: how do nanoparticles affect oogenesis and embryonic development. Oncotarget. 2017; 8(65): 109799-109817 , doi: 10.18632/oncotarget.19087, indexed in $\mathrm{Pu}-$ bmed: 29312650.

45. Cavallin MD, Wilk R, Oliveira IM, et al. The hypothalamic-pituitary-testicular axis and the testicular function are modulated after silver nanoparticle exposure. Toxicol Res (Camb). 2018; 7(1): 102-116, doi: 10.1039/c7tx00236j, indexed in Pubmed: 30090567.

46. Kikuchi M, Yatabe M, Tando Y, et al. Immunohistochemical localization of anterior pituitary hormones in S-100 protein-positive cells in the rat pituitary gland. Cell Tissue Res. 2011; 345(3): 425-429, doi: 10.1007/s00441-011-1214-6, indexed in Pubmed: 21830043.

47. Marin F, Stefaneanu L, Kovacs K. Folliculostellate cells of the pituitary. Endocr Pathol. 1991; 2(4): 180-192, doi: 10.1007/ BF02915206, indexed in Pubmed: 32138407.

48. Vitale ML, Barry A. Biphasic effect of basic fibroblast growth factor on anterior pituitary folliculostellate TtT/GF cell coupling, and connexin 43 expression and phosphorylation. J Neuroendocrinol. 2015; 27(10): 787-801, doi: 10.1111/jne.12308, indexed in Pubmed: 26265106.

49. Amano O, Yoshitake Y, Nishikawa K, et al. Immunocytochemical localization of basic fibroblast growth factor in the rat pituitary gland. Arch Histol Cytol. 1993; 56(3): 269-276, doi: 10.1679/aohc.56.269, indexed in Pubmed: 8240855.

50. Claudius L, Yoshimi Y, Yoichiro H, et al. Phagocytotic removal of apoptotic endocrine cells by folliculostellate cells and its functional implications in clusterin accumulation in pituitary colloids in helmeted guinea fowl (Numida meleagris). Acta Histochem. 2006; 108(1): 69-80, doi: 10.1016/j. acthis.2006.01.006, indexed in Pubmed: 16569423.

Submitted: 7 December, 2020

Accepted after reviews: 3 April, 2021 Available as AoP: 20 April, 2021 